\title{
Obstetrical Acute Kidney Injury: 25 Years' Experience from Nephrology Care Unit in Pakistan
}

\author{
Rubina Naqvi*, Ejaz Ahmed, Rashid Sheikh, Adib Rizvi \\ Sindh Institute of Urology and Transplantation (SIUT), Karachi, Pakistan \\ Email: rubinanaqvi@gmail.com, ${ }^{*}$ naqvirubina@yahoo.com
}

Received 19 July 2015; accepted 10 August 2015; published 13 August 2015

Copyright (C) 2015 by authors and OALib.

This work is licensed under the Creative Commons Attribution International License (CC BY). http://creativecommons.org/licenses/by/4.0/

(c) (i) Open Access

\begin{abstract}
Objective: We aim to report observations from patients who developed acute kidney injury after complicated obstetrics and referred to our institution. Patients and Methods: Observational cohort of patients identified as having acute kidney injury (AKI) in obstetrical situation, at a tertiary center in Pakistan, from January 1990-December 2014. AKI was defined according to RIFLE criteria and patients fall from Risk to Loss category on arrival. On ultrasonography, all women had normal size non obstructed kidneys, and no other co morbid. Results: Between Jan. 1990 to Dec. 2014, 1441 (which is $25.62 \%$ of total AKI) women with obstetrical AKI registered to this hospital. Most common causes were peripartal excessive blood loss, abruptio placentae, intra uterine fetal death, followed by sepsis, pre-eclampsia, eclampsia, abortions, surgical trauma, exposure to nephrotoxic antimicrobials and hemolysis with blood transfusion reaction. There was frequent coexistence of more than one reason in majority of patients. Acute cortical necrosis (ACN) reported on ultrasonography in 420 and on biopsy in 87 women. Renal replacement therapy was required on arrival in $94 \%$ cases. Complete renal recovery observed in $30.98 \%$, while $12.14 \%$ expired during acute phase, renal replacement therapy beyond 90 days required in $20.21 \%$ and $17.67 \%$ disappeared either in state of partial recovery or in the beginning, refusing renal replacement altogether. We divided the population in four groups, from 1990-1999 (10 years), then 2000-2004, 2005-2009 and 2010-2014, each 5 years, and then we compared if there is any change in trends during different time periods. Conclusion: In this part of world, poor health infra structure still causes complications in obstetrical situation which can result deaths in young women or requirement for lifelong renal replacement.
\end{abstract}

\section{Keywords}

AKI, Obstetrical, Pregnancy Related, ACN

${ }^{*}$ Corresponding author.

How to cite this paper: Naqvi, R., Ahmed, E., Sheikh, R. and Rizvi, A. (2015) Obstetrical Acute Kidney Injury: 25 Years' Experience from Nephrology Care Unit in Pakistan. Open Access Library Journal, 2: e1778.

http://dx.doi.org/10.4236/oalib.1101778 


\section{Introduction}

Acute kidney injury (AKI), in association with pregnancy invariably occurs as a result of potentially preventable causes. Availability of health care facilities varies widely in different parts of world, even in same region neighboring countries or different parts of same country can present range of statistics in this regard. In developed world, incidence of pregnancy related AKI fall from 22\% in 1950's to 1\% in 1990s [1], whereas neighboring country India has reported a decline from 15\% - 22\% in 1970s to 9\% - 13\% in 2013 [2] [3]. From Pakistan published reports reveal 11\% - 36\% of total AKI resulted from complicated obstetrics [4] [5] except one weird joint report from two centers in same city, which has reported pregnancy related AKI $0.55 \%$ of total AKI over a period of ten years [6].

The development of AKI in obstetrical patients differs pathogenically in early or late part of pregnancy or postpartum period. During early pregnancy pre-renal AKI may result from hyper emesis or excessive blood loss with abortion. Another mechanism in early part may be related to sepsis which may arise from urinary tract infection or induced abortion. During later part of pregnancy intra renal AKI more prevalent, most addressed condition is pre eclampsia, pathogenesis for which not yet clearly understood, but placental and systemic endothelial activation both play part. Other causes include HELLP syndrome, acute fatty liver, thrombotic microangiopathy, pyelonephritis, and acute tubular necrosis which could be ischemic or related to toxins. Excessive blood loss before or soon after child birth remains main contributing factor to ischemic ATN. While sepsis may cause AKI in multi factorial manner; intra renal hemodynamic changes, endothelial dysfunction, infiltration of inflammatory cells in renal parenchyma, activation of mediators, intraglomerular thrombosis, and tubular obstruction with necrotic debris may all play some part [7]. After child birth that is in post partum period intrinsic causes may carry over including ischemic ATN and sepsis, while post renal AKI may occur in this group, with accidental bilateral ureteric ligation during caesarean section, in few cases.

Present study carried out at this institution, which is a tertiary care center for all kidney ailments and caters patient population from all over the country as providing all renal replacement and associated therapies free of cost. This study highlights the magnitude of pregnancy related AKI, and its trends in prevalence and outcome over a period of two and a half decades.

\section{Patients and Methods}

This is an observational cohort carried out at a tertiary health care center from January 1990 to December 2014. AKI was defined according to RIFLE criteria; that is

Risk: when serum creatinine increased 1.5 times from base line or urine output decreased to less than $0.5 / \mathrm{kg} /$ hour over previous 6 hours.

Injury: when serum creatinine increased 2 times from base line or urine output decreased to less than $0.5 / \mathrm{kg} /$ hour over previous 12 hours.

Failure: when serum creatinine increased 3 times from base line or creatinine $>4 \mathrm{mg} \%$ or urine output decreased to less than $0.3 / \mathrm{kg} /$ hour over previous 24 hours, or anuria over past 12 hours.

Loss: when complete loss of renal function for $>4$ weeks.

All patients included in this study on arrival fall in one of category from Risk to Loss. Only women with recent past history of pregnancy or child birth were included in cohort. This duration ranged from 1 day to 1 month.

Ultrasonography performed on admission revealed normal size non obstructed kidneys, and women had no other co morbid prior to pregnancy. 32 variables were recorded for each patient on day of admission. This includes age, history, duration of insult, oliguria, anuria, Hemoglobin, total leukocyte count, platelet count, PT, APTT, blood Urea, serum Creatinine, serum Sodium, serum Potassium, venous bicarb, serum LDH, serum bilirubin, AST,ALT, $\gamma \mathrm{GT}$, alkaline phosphatase, urine dipstick, urine microscopy, amount of blood transfused before coming to this hospital, ultrasonography, parenteral fluids before renal replacement therapy, renal replacement therapy, sessions of hemodialysis or days on peritoneal dialysis, renal biopsy in selected cases (with de- 
layed recovery and no ultrasonographic evidence of cortical necrosis) and outcome.

All biochemical tests were done on Unicel DxC 800 Synchron Clinical System, Beckman Coulter auto-analyzer.

We divided the population in 4 time periods, for the purpose of observing any change in trends in different causes. Quantitative variables reported as means \pm SD and Qualitative as percentages.

\section{Results}

Between Jan. 1990 to Dec. 2014, 1441 (which is 25.62\% of total AKI) women with obstetrical AKI registered to this hospital. The common causes of AKI at different time periods given in Table 1. Other than abortion there was frequent coexistence of more than one reason in majority of patients, which means a woman with pre-eclampsia might have intrauterine fetal death and excessive blood loss before or after child birth, or a woman with excessive blood loss might have coexisting factor of intrauterine death of fetus, or sepsis (Table 1). Anuria was reported in $42.84 \%$ and oliguria in another $50.88 \%$ patients on presentation. The laboratory parameters of patients on day of admission are given in Table 2, average Hemoglobin of $8.05 \pm 2.18 \mathrm{~g} / \mathrm{dl}$ indicates that majority was anemic on presentation, while average leukocyte count of $19.9 \pm 9.8$ directs towards both presence of infection in some and reactive leucocytosis in others. Thrombocytopenia was a feature in $67.42 \%$ women who

Table 1. Causes of AKI over different time period.

\begin{tabular}{|c|c|c|c|c|c|}
\hline Causes & $\begin{array}{c}1990-1999 \\
\mathrm{~N}=357^{*} \\
\text { (10 years) }\end{array}$ & $\begin{array}{c}2000-2004 \\
N=163^{*} \\
\text { (5 years) }\end{array}$ & $\begin{array}{c}2005-2009 \\
N=286^{*} \\
\text { (5 years) }\end{array}$ & $\begin{array}{c}2010-2014 \\
N=635^{*} \\
\text { (5 years) }\end{array}$ & $\begin{array}{c}\text { Total } \\
\mathrm{N}=1441^{*} \\
\text { (25 years) }\end{array}$ \\
\hline$\%$ of total AKI & 21.64 & 23.86 & 27.44 & 35.27 & 25.62 \\
\hline Abortion & $49(13.7)^{* *}$ & 22 (13.49) & 35 (12.2) & $39(6.1)$ & 145 \\
\hline $\mathrm{APH}$ & 113 & 50 & 83 & 180 & 426 \\
\hline Eclapmsia/PET & 66 & 17 & 37 & 107 & 227 \\
\hline IUD & 145 & 76 & 70 & 291 & 582 \\
\hline $\mathrm{PPH}$ & 117 & 63 & 57 & 167 & 404 \\
\hline Sepsis & 60 & 21 & 51 & 69 & 201 \\
\hline HUS/HELLP & $4(1.1)$ & $7(4.2)$ & $11(3.84)$ & $12(1.88)$ & 34 \\
\hline
\end{tabular}

*Differs from total of numbers given below, as many female had more than one insult; ${ }^{* *}$ Percentages in parentheses.

\begin{tabular}{cc} 
Table 2. Laboratory parameters. & \\
\hline Hb g/dl mean \pm SD & $8.05 \pm 2.18$ \\
WCC mean \pm SD & $19.929 \pm 9.86$ \\
Platelet mean \pm SD & $218.80 \pm 185.101$ \\
Urea mg/dl mean \pm SD & $197.58 \pm 95.30$ \\
Creatinine mg/dl mean \pm SD & $10.28 \pm 7.33$ \\
Na mEq/l mean \pm SD & $134.61 \pm 10.31$ \\
K mEq/l mean \pm SD & $4.976 \pm 1.343$ \\
HCO 3 Eq/L mean \pm SD & $17.65 \pm 8.26$ \\
LDH U/L mean \pm SD & $1739.170 \pm 1611.903$ \\
Bilirubin mg/l mean \pm SD & $2.59 \pm 4.2$ \\
ALT U/L mean \pm SD & $180.623 \pm 474.66$ \\
AST U/L mean \pm SD & $127.313 \pm 326.11$ \\
Alk Phos U/L mean \pm SD & $163.098 \pm 131.671$ \\
\hline
\end{tabular}


expired during acute phase of illness. Average urea of $197.58 \pm 95.3$ and creatinine of $10.28 \pm 7.33$ indicates advanced stage of renal failure in majority. Serum LDH levels also found raised with average of $1739.17 \pm$ 1611.9 U/L (Table 2).

Renal replacement therapy was required on arrival in $94 \%$ cases. Clinical outcome of studied population is given in Table 3. Renal recovery rate rather declined during last decade (was $42.5 \%$ during initial 10 years and $28 \%$ - 31\% during last 10 years. Overall complete renal recovery observed in $30.98 \%$, while $12.14 \%$ expired during acute phase, renal replacement therapy beyond 90 days required in $20.21 \%$ and $17.67 \%$ disappeared either in state of partial recovery or in the beginning, refusing renal replacement altogether (Table 3). Prominent feature of patients who died during acute phase of illness are given in Table 4, 96\% of women who died had decline in urine output from absolute anuria to less than $400 \mathrm{ml} / 24$ hours. Deranged coagulation was a feature in $54.85 \%$ while abnormal platelets in $76 \%$ (majority low counts, some with high counts). Liver dysfunction was noted in $69.71 \%$ women and hyperkalemia in $41.14 \%$. Ventilatory support was required in $37.71 \%$ of deceased women (Table 4).

Acute cortical necrosis (ACN) was reported on ultrasonography in 420 women, it was suspected when hypo echoic rim was noted in cortical region. Histological evidence of ACN found in 87 women. Renal biopsy was done in selected cases where radiology was un-suggestive and patient revealed delayed recovery or urine dipstick shown protein of $4+$.

We divided the population in four groups, from 1990-1999 (10 years), then 2000-2004, 2005-2009 and 20102014, each 5 years, and then we compared if there is any change in trends during different time periods. Abortion as cause of AKI declined from 13.7\% during first decade to $6.1 \%$ in last 5 years. Overall registries have increase to $>100 \%$ over this period, and we have observed increase in numbers of pregnancy related HUS and HELLP syndromes in later one and half decade, then what we use to see during first decade (Table 1).

\section{Discussion}

"The International Society of Nephrology’s 0 by 25 initiative offers a great opportunity to help eliminate disparities in access to and affordability of health care for AKI". This was the message delivered at World Congress of

\begin{tabular}{|c|c|c|c|c|}
\hline & Complete recovery & Partial recovery ${ }^{*}$ & ESRF & Death during acute illness \\
\hline $1990-1999(10$ yr $) \mathrm{n}=357$ & $152(42.5)$ & $80(22.4)$ & $74(20.72)$ & $51(14.2)$ \\
\hline 2000-2004 (5yr) n = 163 & $68(41.7)$ & $34(20.85)$ & $49(30.06)$ & $12(7.3)$ \\
\hline $2005-2009$ (5yr) n = 286 & $81(28.3)$ & $151(52.79)$ & $54(18.88)$ & $30(10.48)$ \\
\hline $2010-2014$ (5yr) n = 635 & $197(31)$ & 253(39.84) & $103(16.22)$ & $82(12.9)$ \\
\hline
\end{tabular}

* Many of these were in recovery phase but never turned up for follow up and thus could not moved to column one.

\begin{tabular}{lc}
$\begin{array}{l}\text { Table 4. Feature in Patients who expired during acute phase of illness } \\
(\mathrm{n}=175) .\end{array}$ \\
\hline Mean age (years) & $27.96 \pm 6.329$ \\
Oliguria (urine $<400 \mathrm{ml} / 24$ hours) & $77(44)$ \\
Anuria (urine $<100 \mathrm{ml} / 24$ hours) & $91(52)$ \\
Hyperkalemia $(\mathrm{K}>5.5 \mathrm{mEq} / \mathrm{l})$ & $72(41.14)$ \\
Deranged Coagulation (INR $>1.4)$ & $96(54.85)$ \\
Thrombocytopenia (platelet $<150)$ & $118(67.42)$ \\
Thrombocytosis (platelet $>350)$ & $15(8.57)$ \\
Deranged Liver Function Tests & $122(69.71)$ \\
Ventilator support required & $66(37.71)$ \\
\hline
\end{tabular}


Nephrology 2015 and a human right case for nephrology been published in Lancet of same month. This study highlights meta-analysis of worldwide epidemiology of AKI [8], still some countries with considerably high morbidity with AKI are missing in this report, mainly because of non publishing the results from such centers.

AKI complicating pregnancy has almost disappeared from some parts of world while still poses remarkable health issue in other. A study published from Morocco in 2013 reveals incidence of pregnancy related AKI 0.66\% (out of 5600 deliveries, 37 developed AKI) [9]. Whereas study published from Nigeria in 2012 revealed 33\% of AKI resulted from pregnancy related complications [10]. A recently published study from Canadian population has shown an increase in pregnancy related AKI from 1.66 to 2.68 per 10,000 deliveries between 2003-04 and 2009-10 (61\% increase, 95\% confidence interval 24\% to 110\%) [11].

Reported prevalence over last six decades varies from 0.55 to $36 \%$ in different settings [5] [6]. A series of 34 cases observed between 1949-1953, was published in 1955 reports mortality of $23.8 \%$ in these women, who were obviously young, as in reproductive age [12]. Later developed world reported significant decline, especially after law of abortion and women attending proper health care facilities for induced abortions [13]. Scenario is different in developing world where not only primary health care facilities are lacking, but induced abortion is considered as taking a life of embryo, an immoral practice. Also from religious point of view a sin in some parts. Geographical distribution and social settings share many similarities between India and Pakistan, (which was united state before 1947) and we will discuss published reports from both countries over last six decades. Chugh et al. reported obstetrical AKI 22.1\% of total AKI in North Indian population in 1976 [2], while same group observed a change in trends in 1989 [14]. Studies published form other parts of India report 9\% 26\% of AKI resulting from complicated obstetrics [15] [16]. From this country published report from northern part reveals pregnancy related AKI 7.4\% - 9.9\% of total AKI [4], where as eastern part reported 19\% [17] and from this center in past we have reported 18\% [18] and 25\% (published data in thesis form). While current study shows rather rise in prevalence and over last five years we have seen pregnancy related AKI increasing to 35\% of total AKI.

Acute cortical necrosis (ACN), is a rare cause of acute renal failure secondary to ischemic necrosis of the renal cortex. The lesions are usually caused by significantly diminished renal arterial perfusion secondary to vascular spasm, micro-vascular injury, or intravascular coagulation. Renal cortical necrosis is usually extensive, although focal and localized forms occur. ACN which leads to unfavorable renal outcome, has been reported as one of renal pathology in pregnancy related AKI, Chugh et al. from India, published a series of 113 cases of ACN and 56.6\% of these were of obstetrical origin [19] whereas another study from Greece around same time period reports obstetrical AKI 9\% of total AKI population and ACN 11\% of obstetrical AKI [20]. In present cohort ACN was reported by radiologists in 420 women, and by pathologists in 87 cases. While we did performed renal biopsy in women where there was no evidence of ACN on radiology and recovery was delayed or they had abnormal protein excretion.

HUS may be difficult to differentiate from severe preeclampsia or HELLP (hemolysis, elevated liver enzyme levels, low platelet count) syndrome and may require postpartum renal biopsy for diagnosis. Renal biopsy in HUS demonstrates glomerular thrombi and fibrin deposition, and fibrinoid necrosis of arterioles. When HUS is suspected, treatment should be initiated with plasma exchange or plasmapheresis [21].

Acute tubular necrosis in late pregnancy most commonly results from preeclampsia, but it can also be caused by HELLP syndrome or by uterine hemorrhage with abruptio placentae. Acute tubular necrosis should be suspected from the clinical situation and confirmed by urinalysis with granular casts and an elevated fractional excretion of sodium (FeNa) [21] [22]. In current study FeNa was checked in those who were able to provide urine sample, and in whom hemodialysis was not started before reaching to this hospital. We have observed increase in number of HUS or HELLP associated AKI in later part of study.

\section{Conclusion}

In contrast to study reported from neighboring country, we have observed rather increase in pregnancy related AKI over last ten years. This is alarming and requires serious measures implementation at national level.

\section{References}

[1] Krane, N.K. (1992) Acute Renal Failure in Pregnancy. Nephrologia, 12, 115-125.

[2] Chugh, K.S., Singhal, P.C., Sharma, B.K., Pal, Y., Mathew, M.T., Dhall, K. and Datta, B.N. (1976) Acute Renal Fail- 
ure of Obstetric Origin. Obstetrics \& Gynecology, 48, 642-646.

[3] Patel, M.L., Sachan, R., Radheshyam and Sachan, P. (2013) Acute Renal Failure in Pregnancy: Tertiary Centre Experience from North Indian Population. Nigerian Medical Journal, 54, 191-195. http://dx.doi.org/10.4103/0300-1652.114586

[4] Ali, A., Zafar, S. and Mehmood, A. (2004) Obstetrical Acute Renal Failure from Frontier Province: A Three Years Prospective Study. Journal of Postgraduate Medical Institute, 18, 109-117.

[5] Ansari, M.R. and Laghari, M.S. (2008) Acute Renal Failure in Pregnancy: One Year Observational Study at Liaquat University Hospital, Hyderabad. Journal of Pakistan Medical Association, 58, 61-64.

[6] Rabbani, M.A., Habib, H.B., Siddiqui, B.K., Tahir, M.H., Ahmad, B., Murtaza, G., Maria, Q. and Ahmad, A. (2008) Etiology of Acute Renal Failure in a Tertiary Center. Saudi Journal of Kidney Diseases and Transplantation, 19, 10091014.

[7] Zarjou, A. and Agarwal, A. (2011) Sepsis and Acute Kidney Injury. JASN, 22, 999-1006. http://dx.doi.org/10.1681/ASN.2010050484

[8] Mehta, R.L., Cerdá, J., Burdmann, E.A., Marcello Tonelli, M., et al. (2015) International Society of Nephrology’s 0by25 Initiative for Acute Kidney Injury (Zero Preventable Deaths by 2025): A Human Rights Case for Nephrology. The Lancet, in Press.

[9] Arrayhani, M., Youbi, R.E. and Sqalli, T. (2013) Pregnancy-Related Acute Kidney Injury: Experience of the Nephrology Unit at the University Hospital of Fez, Morocco. ISRN Nephrology, 2013, Article ID: 109034.

[10] Okunola, O.O., Ayodele, O.E. and Adekanle, A.D. (2012) Acute Kidney Injury Requiring Hemodialysis in the Tropics. Saudi Journal of Kidney Diseases and Transplantation, 23, 1315-1319.

[11] Mehrabadi, A., Liu, S., Bartholomew, S., Hutcheon, J.A., Magee, L.A., Kramer, M.S., Liston, R.M. and Joseph, K.S. (2014) Hypertensive Disorders of Pregnancy and the Recent Increase in Obstetric Acute Renal Failure in Canada: Population Based Retrospective Cohort Study. British Medical Journal, 349, g4731. http://dx.doi.org/10.1136/bmj.g4731

[12] Russell, K.P., Maharry, J.F. and Stehly, J.W. (1955) Acute Renal Failure as an Obstetric Complication. The Journal of the American Medical Association, 157, 15-20. http://dx.doi.org/10.1001/jama.1955.02950180017004

[13] Turney, J.H., Ellis, C.M. and Parsons, F.M. (1989) Obstetric Acute Renal Failure 1956-1987. British Journal of Obstetrics and Gynaecology, 96, 679-687. http://dx.doi.org/10.1111/j.1471-0528.1989.tb03282.x

[14] Chugh, K.S., Sakhuja, V., Malhotra, H.S. and Pereira, B.J. (1989) Changing Trend in Acute Renal Failure in ThirdWorld Countries: Chandigarh Study. Quarterly Journal of Medicine, 73, 1117-1123.

[15] Jayakumar, M., Prabahar, M.R., Fernando, E.M., Manorajan, R., Venkatraman, R. and Balaraman, V. (2006) Epidemiologic Trend Changes in Acute Renal Failure-A Tertiary Center Experience from South India. Renal Failure, 28, 405-410. http://dx.doi.org/10.1080/08860220600689034

[16] Goplani, K.R., Shah, P.R., Gera, D.N., Gumber, M., Dabhi, M., Feroz, A., Kanodia, K., Suresh, S., Vanikar, A.V. and Trivedi, H.L. (2008) Pregnancy-Related Acute Renal Failure: A Single-Center Experience. Indian Journal of Nephrology, 18, 17-21. http://dx.doi.org/10.4103/0971-4065.41283

[17] Rashid, H., Akram, M. and Malik, M.B. (2013) Acute Renal Failure in Pregnancy, Its Causes and Outcome, One Year Study at Shaikh Zayed Hospital Lahore. Annals, 19, 33-36.

[18] Naqvi, R., Akhtar, F., Ahmed, E., Sheikh, R., Ahmed, Z., Naqvi, A. and Rizvi, A. (1996) Acute Renal Failure of Obstetric Origin during 1994 at One Center. Renal Failure, 18, 681-683. http://dx.doi.org/10.3109/08860229609047694

[19] Chugh, K.S., Jha, V., Sakhuja, V. and Joshi, K. (1994) Acute Renal Cortical Necrosis-A Study of 113 Patients. Renal Failure, 16, 37-47. http://dx.doi.org/10.3109/08860229409044846

[20] Alexopoulos, E., Tambakoudis, P., Bili, H., Sakellariou, G., Mantalenakis, S. and Papadimitriou, M. (1993) Acute Renal Failure in Pregnancy. Renal Failure, 15, 609-613. http://dx.doi.org/10.3109/08860229309069411

[21] Krane, N.K. and Batuman, V. (2013) Renal Disease and Pregnancy. Medscape.

[22] Fakhouri, F., Vercel, C. and Frémeaux-Bacch, V. (2012) Obstetric Nephrology: AKI and Thrombotic Microangiopathies in Pregnancy. Clinical Journal of the American Society of Nephrology, 7, 2100-2106. http://dx.doi.org/10.2215/cjn.13121211 


\section{Abbreviations Used in Article}

ACN $=$ Acute cortical necrosis

ALT $=$ Alanine aminotransferase

AKI = Acute kidney injury

APTT = Activated partial thromboplastin time

AST = Aspartate aminotransferase

ATN = Acute tubular necrosis

$\gamma \mathrm{GT}=$ Gamma-glutamyl transferase

HELLP = Hemolysis, elevated liver enzymes and low platelet

HUS = Hemolytic uremic syndrome

$\mathrm{PT}=$ Prothrombin time

$\mathrm{SD}=$ Standard deviation 